\title{
Neuroligical Disorders Due To Malnourishments
}

\author{
Aishvarya Pandey ${ }^{1}$, Pradip Jain ${ }^{2}$ and Praful Patel ${ }^{3}$ \\ ${ }^{1}$ MBBS studentDatta Meghe Medical College, Shalinitai Meghe \\ Hospital and Research Centre, Nagpur, India \\ ${ }^{2}$ Dept. of Biochemistry Datta Meghe Medical College, Shalinitai \\ Meghe Hospital and Research Centre, Nagpur, India \\ ${ }^{3}$ Dept. of Microbiology Jawaharlal Nehru Medical College, Datta \\ Meghe Institute of Medical Sciences Sawangi (Meghe), Wardha \\ Corresponding author email: drpradipjain88@gmail.com
}

\section{ABSTRACT}

The most common neuromuscular disorders leading to dysphagia are myasthenia gravis, amyotrophic lateral sclerosis, Guillain-Barre syndrome, and their variants. All these diseases may easily affect swallowing muscles.Macronutrients and micronutrients are two types of dietary nutrients required by living organisms, especially humans. The macronutrients are the energy-producing nutrients - proteins, carbohydrates, and fats.Micronutrients are vitamins and minerals, while macronutrients are carbohydrates and fat.Both macronutrient and micronutrient deficiencies are referred to as malnutrition. Problems with macronutrients and micronutrients often coexist in humans, making it difficult to distinguish between the two.

KEY WORDS: HIDDEN HUNGER, PELLAGRA, DEMENTIA, PARESTHESIA, NEURAL TUBE DEFECT, WERNICKE -KORSAKOFF SYNDROME, SPINA BIFIDA.

\section{INTRODUCTION}

Malnutrition means deficiency, excess or imbalance of an individual key nutrient or a particular group of vitamins and nutrients that are needed by the body for its proper growth and development. Around the world 780 million are malnourished. India has $23.8 \%$ of the global burden of malnourishment (Luis et al., 2019; Thakur et al., 2020; Ezzati et al., 2002). Nutritional Neurological disorder are the disorders which are caused in an individual due to deficiency of these basic nutrients or vitamins and can cause temporarily or permanently damage to the brain which will ultimately lead to disorders like dementia, pellagra, cretinism-endemic mental retardation. It is also,susceptible to geriatric patients with neurological

Biosc Biotech Res Comm P-ISSN: 0974-6455 E-ISSN: 2321-4007

\section{crossef}

Identifiers and Pagination

Year: 2021 Vol: 14 No (6) Special Issue

Pages: $45-48$

This is an open access article under Creative

Commons License Attribn 4.0 Intl (CC-BY).

DOI: $h t t p: / / d x . d o i . o r g / 10.21786 / b b r c / 14.6 .10$ diseases (Thakur et al., 2020; Ezzati et al., 2002; Database, 1993; Grantham-McGregor et al., 1993).

\section{Symptoms :-}

1. Loss of muscle coordination

2. Abnormal eye movement

3. Delusion or mental confusion

4. Memory loss

5. Paresthesia

7. Bradykinesia

8. Mental Retardation

9. Dysarthria

10. Seizerus

Although a well explained definition of malnutrition that reluctantly expresses its consequences and pathophysiology is not present, the most recognizable way to express it is by saying -deficiency of energy and protein that is required by our body for its normal functioning (Aradhey Parag et al., 2020; OrdunezGarcia PO et al., 1996; Neumann et al., 1979). The basic calories needed by our body to perform its daily chorus
6. Ataxia

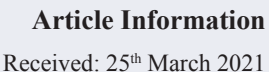

ccepted after revision: $30^{\text {th }}$ May 2021 
is 2200 calories. Which includes carbohydrates-45-55\%, fats-20-35\%, proteins-10-35\%, vitamins. Without that our body will not be in its shape to perform its work (Grantham-McGregor et al., 1991; Malouf et al., 2003; Mishra et al., 2018).

In low-income countries getting two times meal is their main aim. What nutrient they get from them is never taken care of this is the main reason due to which they end up getting malnourished.People are not able to differentiate what is important for their body and its sound working. This scenario is not only seen in developing countries but also in developed countries. This happens due to lack of knowledge about the balance diet and vitamins that are compulsorily needed by our body.192 million children suffer from protein-energy malnutrition (PEM), and over 2000 million experience micronutrient deficiencies (Jyoti et al., 2018; Eichholzer et al., 2006; Malouf et al., 2003; RuchiraShrikant et al., 2020). Hidden hunger means the quality of food do not meet the basic quantity of vitamins and minerals which are needed by our body for its proper growth and development. This is also reason behind malnutrition because an individual can 't measure the percentage of nutrient present its diet. So finding out which vitamin or mineral is lacking is another tough challenge (Gupta et al., 2020; Jyoti et al., 2018; Eichholzer et al., 2006).

From conception till the child reaches the age of three is the peak point because during this period the brain is underdevelopment, and the nutrients need for its proper developmentduring this period is provided firstly form mother and then from the balance diet. In humans, short apical dendrites, fewer spines, and dendritic spine abnormalities occur in severe infant malnutrition. Neurotransmitter alterations appear to persist after nutritional recovery as reflected by diminished sensitivity of cortical structures to basal electrophysiological stimulation (Malouf et al., 2003; RuchiraShrikant et al., 2020). The neurological disorders and syndromes caused by the deficiency of these vitamins are:-

Wernicke-Korsakoff syndrome- is an neurological disorder which happens due to deficiency of Thiamine (B1) in our body. In it there are necrosis of both neuronal and oligodendroglia elements in the mammillary body, superior cerebellar vermis, and hypothalamus. Only 20 $\%$ of cases can get recognized during life. 19\% of then don't even have any clinical signs in them. This disease is a classic triad of ophthalmoplegia, gait ataxia, and confusion. Korsakoff psychosis refers to impairment of short-term memory and confabulation. Wernicke is specifically related to thiamine deficiency (Reilly, 2004; Acton, 1922; Dwivedi and Prasad 1964; Amighi et al., 2004). Neuropathic Beri-Beri -is a degenerative disorder of the peripheral nerve some aspects of motor disability constitute the complaints. Crucial change can be seen in the distal part of the lager myelinated fibers in the crural to some extend in brachial nerve.

The primary symptoms are distal portion of limbs, weakness and Paresthesia. It is also caused by deficiency of thiamine (B1). Symptomatology of Beri-Beri is diverse and many of them are asymptomatic hence evidences of peripheral nerve affection is only found on clinical examination (Rayman, 2000; Reilly, 2004; Acton, 1922; Dwivedi and Prasad 1964; Amighi et al., 2004).

Pellagra- this is caused dur to deficiency of Niacin or vitamin (B3), mainly marked by the three D's dementia, diarrhea, dermatitis. It causes spinal cord manifestation,generally symptoms of myelopathy are referable to both posterior and lateral columns .it also affects the peripheral nerves. If left untreated symptoms can lead to dementia. It also affects the skin and the digestive system (Beaglehole, 2004). Epilepsia- is a condition which causes seizures in children which occurs due to deficiency of pyridoxine or vitamin (B6) in the body of the infant. This is one of the most common disorder od nervous system (Rayman, 2000; Reilly, 2004).

Subacute Combined Degeneration of Spinal Cord -this is caused by deficiency of Cobalamin or vitamin (B12) .in this the disorders of CNS and PNS myelin is seen. The primary signs are seen due to demyelination of peripheral or sensory tracts of the spinalcord.as it progress in an individual it causes spastic paraparesis with weakness and it also increase muscle tone in lower extremities like loss of extensor plantar responses and impaired bowl and bladder movement (Grantham-McGregor et al., 1991; Aradhey, Parag et al., 2020; OrdunezGarcia et al., 1996). Reversible Leukoencephalopathy -deficiency of Cobalamin is the main cause of it. Its symptoms are irritability, apathy, somnolence, excessive fatigue, paranoia, confusion state. This happens due to demyelination in the deep white matter of the cerebral hemisphere .it even cause visual impairment in an individual also known as optical neuropathy (GranthamMcGregor et al., 1991; Aradhey, Parag et al., 2020; Ordunez-Garcia et al., 1996; Amighi et al., 2004).

Neural Tube Defect -deficiency of folate is the cause behind it. The malformation of the brain, spinal cord, skull is the result of neural tube defect. Folate is required for new cell formation so its deficiency will now allow the child growth properly and it also play a main role in DNA Replication.The two most common defects are of spine (spina bifida) and brain is (anencephaly) (Jain, Jyoti et al., 2018; Eichholzer et al., 2006; Malouf et al., 2003). Iodine deficiency is also important cause of mental retardation At least 120000 children every year are born cretins - mentally retarded, physically stunted, deaf-mute or paralysed - as a result of iodine deficiency. Annually an average of 60000 miscarriages and neonatal deaths occurs due to iodine deficiency (Beaglehole, 2014; Kelly, 2004). Selenium Deficiency - is the cause behind random and adverse mood swings.

\section{DISCUSSION}

These are few of the neurological disorders causes by the deficiency of nutrients in our body. This can be overcome by providing the individual with the food that 
has that particular group of nutrients. There diagnosis is the most important thing if diagnosed early its can be treated permanently and it won't end up fatal (Ezzati et al., 2002). For preventing such conditions mother should take proper diet and care of herself this will reduce $50 \%$ chances of underdevelopment of the baby. Every individual of any age can get malnourished if balanced diet is not taken. Even the rich or middle people can suffer from it if they don't have a balanced diet (Kelly et al., 2004; Mintzer et al., 2006).

Above mentioned neurological disorders can be treated after proper clinical diagnosis.

There treatment are as follows :-

Wernicke -Korsakoff syndrome- it can be treated by administration of $100 \mathrm{mg}$ of thiamine then intravenous fluid dextrose because for the proper metabolism of carbohydrates thiamine is required as a cofactor (Beaglehole, 2014; Kelly, 2004; Mintzer et al., 2006; Sener et al., 2006). Neuropathic Beri-Beri-individual should be provided with required quantity of vitamin B. Aspirin or acetaminophenin a know quantity will be sufficient for hyperpathia sometimes 15 to $30 \mathrm{mg}$ of codeine is also given. Some food items which are used for curing the disease are fish, dairy, nuts, whole grains (Kelly et al., 2004). Pellagra- Proper diet enriched with niacin should be taken. For formation of nicotinic acid pyridoxine is also essential so it should be taken care that the individual take vitamin B6 and B3 together. Some food products that are rich in nicotinic acid are nutritional yeast, eggs, bran, peanuts, meat, poultry, fish with red meat, cereal (Beaglehole, 2014; Kelly, 2004; Mintzer et al., 2006; Sener et al., 2006).

Infant Seizures- supplementation with $15 \mathrm{mg} /$ per day of pyridoxine is needed. Ketones van also be used to prevent seizures the ratio of fat and proteins should be 4:1. The child should be provided with meat, cheese, high-fiber vegetables (Earthscan, 2005). Subacute Combined Degeneration of Spinal Cord- it can be cured by providing the individual with vitamin B12 dose. it is of two types reversible and irreversible. in irreversible type lifelong doses of vitamin B12 will be needed and in reversible one $1 \mathrm{mg}$ of cobalamin is inserted intramuscularly for seven days then the dose is reduced to $1 \mathrm{mg}$ weekly for one month (Kelly et al., 2004). Iodine deficiency - it can be cured by taking substances rich in iodine and specially during pregnancy it should be taken care that the mother has sufficient amount of iodine in their diet. Some food items which are rich in iodine are as follows fish (tuna), sea weeds, sea food. Even dairy items are help full like curd, milk, butter, cheese. This type of diet if taken during pre-pregnancy will reduce the chances of neonatal deaths (Mintzer et al., 2006; Sener et al., 2006; Earthscan, 2005).

Selenium deficiency- its causes mood swings in an individual supplements rich in selenium and vitamin if given together can control these mood swings. Some food supplements rich in it are chicken, fish, seafood, nuts, beans etc.Generally, the information about selenium is not available and only present in traces (Grantham-
McGregor et al., 1991; Aradhey, Parag et al., 2020). Disorders related to malnutrition are mostly preventable and causes moderate to fatal effects to an individual. Dementia is one of its fatal disorders.

\section{CONCLUSION}

Hence, we conclude that our body needs proper amount of vitamin and nutrients for its sound working many of them are needed in traces but till are very important for the functioning working of our Central Nervous System and Peripheral Nervous System. Most importantly it was seen that most of the neurological disorders are curable if taken care at their primary stage with the help of clinical treatment and in the form of food products. The common food products that we saw were dairy items like milk, butter, cheese and sea food, meat and fish so it so be taken on daily basis.

\section{REFERENCES}

Abhishek, G., Jajoo, S.N., (2020) Intrascrotal Solitary Neurofibroma. JOURNAL OF CLINICAL AND DIAGNOSTIC RESEARCH, 14(6), pp.6-8.

Amighi, J., Sabeti, S., Schlager, O., Mlekusch, W., Exner, M., Lalouschek, W., Ahmadi, R., Minar, E. and Schillinger, M., 2004. Low serum magnesium predicts neurological events in patients with advanced atherosclerosis. Stroke, 35(1), pp.22-27.

Ankar, R.S., Seema, S., (2020). Chemotherapy Induced Peripheral Neuropathy - A Review. Journal Of Evolution Of Medical And Dental Sciences-Jemds, 9(42), pp.314751.

Aradhey, P., Bakre, A., Kumar, S. and Acharya, S., 2020. Clinical profile of Uremic polyneuropathy in Chronic Kidney Disease patients. Medical Science, 24(102), pp.945-951.

Beaglehole, R., 2004. Responding to the dual burden of nutritional diseases. Asia Pacific Journal of Clinical Nutrition, 13.

Database on Child Growth. 1993, Bulletin of the World Health Organization, 71, pp.703-7.

Dhobe, M.S., Gujar, S. and Patil, M., 2020. PREVALENCE OF ASSOCIATED FACTORS OF DEPRESSIVE SYMPTOMS AMONG SCHOOL GOING CHILDREN'S. International Journal of Modern Agriculture, 9(3), pp.31-35.

Dwivedi, M.P. and Prasad, B.G., 1964. An epidemiological study of lathyrism in the district of Rewa, Madhya Pradesh. Indian Journal of Medical Research, 52, pp.81116.

Eichholzer, M., Tönz, 0. and Zimmermann, R., 2006. Folic acid: a public-health challenge. The Lancet, 367(9519), pp.1352-1361.

Ezzati, M., Vander Hoorn, S., Rodgers, A., Lopez, A.D., Mathers, C.D., Murray, C.J. and Comparative Risk Assessment Collaborating Group, 2003. Estimates of global and regional potentil health gains from reducing muliple major risk factors. The Lancet, 362(9380), pp.271-280. 
Grantham McGregor, S.M., Powell, C.A., Walker, S.P., Himes, J.H. and McDonald, K., 1991. Nutritional supplementation, psychosocial stimulation and development of stunted children: the Jamaican studyabstract. West Indian med. j, pp.15-16.

Hunger, T.F., 2005. Halving Hunger: It Can Be Done (London and Sterling, VA: Earthscan, James and James).

Jain, J., Banait, S., Tiewsoh, I. and Choudhari, M., 2018. Kikuchi's disease (histiocytic necrotizing lymphadenitis): A rare presentation with acute kidney injury, peripheral neuropathy, and aseptic meningitis with cutaneous involvement. Indian Journal of Pathology and Microbiology, 61(1), p.113.

Kelly, P.J., Kistler, J.P., Shih, V.E., Mandell, R., Atassi, N., Barron, M., Lee, H., Silveira, S. and Furie, K.L., 2004. Inflammation, homocysteine, and vitamin B6 status after ischemic stroke. Stroke, 35(1), pp.12-15.

Latchoumi, T.P., Ezhilarasi, T.P. and Balamurugan, K., 2019. Bio-inspired weighed quantum particle swarm optimization and smooth support vector machine ensembles for identification of abnormalities in medical data. SN Applied Sciences, 1(10), pp.1-10.

Major Hugh W Acton, I.M.S., 1922. An investigation into the causation of lathyrism in man. The Indian medical gazette, 57(7), p.241.

Malouf, R. and Evans, J.G., 2003. Vitamin B6 for cognition. Cochrane Database of Systematic Reviews, (4).

Malouf, R. and Sastre, A.A., 2003. Vitamin B12 for cognition. Cochrane Database of Systematic Reviews, (3).
Mintzer, S., Boppana, P., Toguri, J. and DeSantis, A., 2006. Vitamin D levels and bone turnover in epilepsy patients taking carbamazepine or oxcarbazepine. Epilepsia, 47(3), pp.510-515.

Neumann, C.G., Swendseid, M.E., Jacob, M., Stiehm, E.R. and Dirige, O.V., 1979. Biochemical evidence of thiamin deficiency in young Ghanaian children. The American journal of clinical nutrition, 32(1), pp.99-104.

Ordúñez-García, P.O., Nieto, F.J., Espinosa-Brito, A.D. and Caballero, B., 1996. Cuban epidemic neuropathy, 1991 to 1994 : history repeats itself a century after the" amblyopia of the blockade". American journal of public health, 86(5), pp.738-743.

Rayman, M.P., 2000. The importance of selenium to human health. The lancet, 356(9225), pp.233-241.

Reilly, C., 2008. The nutritional trace metals. John Wiley et Sons.

Rodríguez-Salinas, L.C., Amador, C. and Medina, M.T., 2000. Malnutrition and neurologic disorders: a global overview. Neurologic Consequences of Malnutrition, p.1.

Sener, U., Zorlu, Y., Karaguzel, O., Ozdamar, O., Coker, I. and Topbas, M., 2006. Effects of common anti-epileptic drug monotherapy on serum levels of homocysteine, vitamin B12, folic acid and vitamin B6. Seizure, 15(2), pp.79-85.

Thakur, Sumit, Ashish, Varma, Sachin Damke, RevatMeshram, and BhavanaLakhkar. 2020. Identifying Prevalence, Aetiology and Associations in Malnourished Hospitalized Children: A Cross-Sectional Study. Medical Science, 24 (106), pp. 4663-71. 